\title{
Surveillance Evaluation for Severe Acute Respiratory Infection, Sana'a city, Yemen, 2021
}

Manal Abdo Mahsoon, MSc; Mohammed Al Amad, MSc

Yemen Field Epidemiology Training Program, Sana'a, Yemen

Corresponding Author:

Manal Abdo Mahsoon, MSc

Yemen Field Epidemiology Training Program

Al- rabat Street

Sana'a

Yemen

Phone: 967776740969

Email: Manalmahsoon@gmail.com

\section{Abstract}

Background: Due to the war and limited access to health facilities, the surveillance of severe acute respiratory infection (SARI) has been expanded to include all hospitals since 2017.

Objective: We aimed to assess the usefulness of SARI surveillance in Sana'a city and to assess its performance in terms of attributes.

Methods: The Centers for Disease Control and Prevention's updated guideline was used for evaluating surveillance systems. Four qualitative attributes, including stability, simplicity, flexibility, and acceptability, and data quality as a quantitative attribute were assessed. An in-depth interview with stakeholders at the central level and self-administered questionnaires with 5 Likert scales and a register review at the peripheral level were used for collecting data. Scores for indicators were used to calculate the total gained scores for each attribute and percentages for ranking them as poor $(<60 \%)$, average $(60 \%$ to $<80 \%)$, good $(80 \%$ to $<90 \%)$, and excellent $(\geq 90 \%)$.

Results: SARI surveillance was useful and obtained a total gained score of $94 \%$. The overall performance of the five attributes was average (64\%). It was good (82\%) at the central level where flexibility was excellent (93\%) and stability was average (72\%). The performance at the peripheral level was poor (51\%); simplicity (61\%) and acceptability (74\%) were average, and the data quality was poor (20\%).

Conclusions: Expanding SARI surveillance with a lack of staff training, central communication, and supervision might be the main reason for its weak performance at the peripheral level. Supporting SARI program activities and selecting SARI reporting sites and the surveillance team at each site based on World Health Organization criteria are highly recommended.

(iproc 2022;8(1):e36458) doi: $10.2196 / 36458$

\section{KEYWORDS}

evaluation; national influenza control program; CDC guidelines; Sana'a; Yemen

Edited by Y Khader; this is a non-peer-reviewed article. Submitted 15.01.22; accepted 17.01.22; published 03.02.22.

Please cite as:

Mahsoon MA, Al Amad M

Surveillance Evaluation for Severe Acute Respiratory Infection, Sana'a city, Yemen, 2021

iproc 2022;8(1):e36458

URL: https://www.iproc.org/2022/1/e36458

doi: $10.2196 / 36458$

PMID: 
CManal Abdo Mahsoon, Mohammed Al Amad. Originally published in Iproceedings (https://www.iproc.org), 03.02.2022. This is an open-access article distributed under the terms of the Creative Commons Attribution License (https://creativecommons.org/licenses/by/4.0/), which permits unrestricted use, distribution, and reproduction in any medium, provided the original work, first published in Iproceedings, is properly cited. The complete bibliographic information, a link to the original publication on https://www.iproc.org/, as well as this copyright and license information must be included. 